Editorial

\title{
Youth Digital Participation: Now More than Ever
}

\author{
Neta Kligler-Vilenchik ${ }^{1, *}$ and loana Literat ${ }^{2}$ \\ ${ }^{1}$ Department of Communication and Journalism, Hebrew University of Jerusalem, 9190501 Jerusalem, Israel; \\ E-Mail: neta.kv@mail.huji.ac.il \\ 2 Teachers College, Columbia University, New York, NY 10027, USA; E-Mail: literat@tc.columbia.edu \\ * Corresponding author
}

Submitted: 21 April 2020 | Published: 19 May 2020

\begin{abstract}
One of the far-reaching implications of the current global COVID-19 pandemic has been the sudden boost in use of digital media due to social distancing and stay-at-home orders. In times of routine, youth are often the first to adopt new technologies and platforms, to experiment with modes of production and practices of sharing, and often spend significant time and energy socializing online. Now such digital practices have become common among much wider demographics. Moreover, the move to online learning in schools and the spurt of innovative digital experiences offered has abruptly shifted the rhetoric of concern often associated with youth's so-called "screen time." The articles in this thematic issue-though written long before the COVID-19 pandemic-address many of the questions that now are significantly brought to the forefront. What are the potentials and opportunities offered by youth digital participation for learning, for self-expression, for identity formation, and for social connection? How does digital participation shape civic and political life? And finally, especially when digital participation is so ever-present, what are barriers to youth participation online, and what are the challenges and risks it poses?
\end{abstract}

\section{Keywords}

covid-19; digital opportunities; digital participation; digital risks; online learning; screen time; youth; youth political participation

\section{Issue}

This editorial is part of the issue "Youth Digital Participation: Opportunities, Challenges, Contexts, and What's at Stake" edited by Neta Kligler-Vilenchik (Hebrew University of Jerusalem, Israel) and Ioana Literat (Teachers College, Columbia University, USA).

(C) 2020 by the authors; licensee Cogitatio (Lisbon, Portugal). This article is licensed under a Creative Commons Attribution 4.0 International License (CC BY).

\section{Introduction}

We are writing the introduction to this thematic issue in April 2020, at what may be the height of the global COVID-19 pandemic. Around the globe, nearly 3 billion people are in some form of lockdown, and are ordered to stay at home. One of the far-reaching implications of this crisis has been the sudden boost in use of digital media among the entire population and, naturally, among one of its trailblazing demographics-youth. In times of routine, youth are often the first to adopt new technologies and platforms, to experiment with modes of production and practices of sharing, and often spend significant time and energy socializing online (Ito et al., 2009, 2019; Jenkins, Shresthova, Gamber-Thompson, Kligler-Vilenchik, \& Zimmerman, 2016). Now such digital practices have become the daily bread-and-butter for much wider demographics, including younger children and older adults. Moreover, the move to online learning in schools around the world, and the spurt of innovative digital experiences offered-from online yoga classes to virtual museums-has abruptly shifted the rhetoric of concern often associated with youth's so-called "screen time" (see Blum-Ross \& Livingstone, 2016). The ways in which children and youth play and socialize digitally, which only a few weeks ago were a cause of worry, are 
now accepted not only as legitimate, but as an essential connection to educational, social, and cultural life.

The articles in this thematic issue were all written long before the COVID-19 pandemic, and thus do not directly touch on the ways in which digital practices might be shifting or evolving in its aftermath. Yet, at the same time, the topics discussed in the thematic issue address many of the questions that now are significantly brought to the forefront. What are the potentials and opportunities offered by youth digital participation for learning, for self-expression, for identity formation, and for social connection? How does digital participationcurrently the main form of participation available to most of us-shape civic and political life, including civic learning, cross-cutting exposure, and political socialization? And finally, especially when digital participation is so ever-present, what are barriers to youth participation online, and what are the challenges and risks it poses?

\section{Youth Digital Participation: An Overview of the Thematic issue}

The five contributions to this thematic issue represent a range of geographical contexts, methodological approaches (surveys, content analyses, ethnographic approaches), and foci (opportunities and risks, politics and activism, learning outcomes). Taken together, they paint a rich, nuanced picture of youth digital participation in the current age.

One of the key themes in research on youth digital participation is striking a balance between the opportunities offered by digital media participation and the risks inherent in participation-ranging from privacy risks to psychological risks that may compromise wellbeing. In the first article of this thematic issue, Vissenberg and d'Haenens (2020) consider the trade-off between digital opportunity and risk empirically, focusing on the concept of online resilience. As the authors show through a survey of Flemish youth, engaging with myriad activities online inevitably comes with increased exposure to risky online content, that may cause feelings of harm. Yet, structural equation modeling shows that online resiliencethe ability to effectively cope with online risks and deal with their negative consequences-moderates this association, so that the opportunities of participation outweigh harms to youths' wellbeing.

Reinikainen, Kari, and Luoma-aho (2020) consider online opportunities (and risks) in a different, specific context-young people's relationship with brands on social media. Aiming to understand youth perspectives on this relationship, these authors surveyed Finnish and British youth about their perception of organizational listening, that is, to what extent youth trust the information provided by brands, whether they feel brands show interest in people, and who they believe benefits from brands' presence on social media. The results show that youth are fairly skeptical about the way brands use social media to connect with them, and saw brand presence on social media as beneficial mostly to the brands; this was particularly true the younger the respondents. Those with higher perceptions of organizational listening also showed higher levels of trust towards brands-as well as towards authorities and non-profit organizationspointing to potential societal benefits of active listening to young people on social media.

In addition to commercial brands, another stakeholder attempting to forge relationships with young people through social media are politicians. For politicians, social media offer a way to communicate with citizensincluding young citizens-directly, circumventing the influence of traditional news outlets. Surveying Danish youth, Marquart, Ohme, and Möller (2020) investigate to what extent young Danes follow politicians on social media, and how this is related to their civic messaging and campaign participation. The authors find that following politicians on social media is related to increased campaign engagement, but it is youths' friends and followers who are the main node in their political online networks. At the same time, they find that traditional media lose their influence as primary information sources for young citizens, which may raise concerns about increasing power of populist rhetoric and the spread of misinformation.

In terms of political participation, social media can be not only a space to receive and consume political messages, but also to actively campaign and advance political aims. Climate change is currently one of the most prominent causes associated with youth activism, with Swedish teenager Greta Thunberg its salient symbol. Boulianne, Lalancette, and Ilkiw (2020) consider the School Strike for Climate movement, initiated by Thunberg, and its use of Twitter. Employing a combination of qualitative and quantitative analysis, the authors analyze the functions of tweets connected to this movement, finding that they aim not only to share information, but particularly to document local events from across the globe. This function helps shape the movement as a global one, with international protest events connected to each other through social media and other digital media tools.

The final contribution to this thematic issue, analyzing youth digital participation in the form of online journalism, brings youth voices to the forefront. The five authors of this contribution include an adult adviser (Dzula) and four youth co-authors-Chen, Cook, Luna, and Wuu. Together, Dzula et al. (2020) examine the affordances and constraints offered by high school journalism programs. Through a qualitative study incorporating group interviews, reflection prompts, and participant observation, the authors ask how journalism programs can amplify student voice, but also how they may unduly limit students' self-expression. Through a process of collaborative research and writing, the authors qualitatively analyzed the various affordances and constraints of high school journalism, leading them to consider the concept of "risk context" - the vulnerability of an actor, 
brought on by digital participation. This concept allows them to acknowledge that not all digital participation is inherently positive, while pushing to maximize affordances and mitigate constraints. This contribution thus incorporates several of the key themes of the issuerisks and opportunities, civic participation, and learning outcomes-while highlighting the youth perspective: Here, youth are not only the object of research, but the researchers themselves. We commend the team for this endeavor and hope to see more youth-authored research in the future.

We see the work conducted in this thematic issue as a significant contribution to the already rich area of youth digital participation. As research has shown, youth digital participation facilitates opportunities in areas such as learning and professional development (e.g., Ito et al., 2019), self-expression and identity exploration (e.g., Renninger, 2015), social connection (e.g., Weinstein, 2018), as well as for civic and political participation and expression (e.g., Kligler-Vilenchik \& Literat, 2018). At the same time, youth digital participation should not be uncritically celebrated: Rather, researchers should be cognizant of the nuances of youth participation and a focus on when, how, why and for what youth digital participation matters (Literat, Kligler-Vilenchik, Brough, \& Blum-Ross, 2018). These questions are imperative, now more than ever.

\section{Acknowledgments}

The authors are grateful to Henry Jenkins for all the ways in which he has shaped and supported their individual and collaborative work around youth digital participation.

\section{Conflict of Interests}

The authors declare no conflict of interests.

\section{References}

Blum-Ross, A., \& Livingstone, S. (2016). Families and screen time: Current advice and emerging research. London: London School of Economics and Political Science. Retrieved from http://eprints.Ise.ac. uk/66927/1/Policy\%20Brief\%2017-\%20Families\%20 \%20Screen\%20Time.pdf
Boulianne, S., Lalancette, M., \& Ilkiw, D. (2020). "School Strike 4 Climate": Social media and the international youth protest movement on climate change. Media and Communication, 8(2), 208-218.

Dzula, M., Chen, S., Cook, A., Luna, J., \& Wuu, S. (2020). Digital participation and risk contexts in journalism education. Media and Communication, 8(2), 219-231.

Ito, M., Baumer, S., Bittani, M., Cody, R., Stephenson, B. H., Horst, H. A., . . . Tripp, L. (2009). Hanging out, messing around, and geeking out: Kids living and learning with new media. Cambridge: MIT Press.

Ito, M., Martin, C., Pfister, R. C., Rafalow, M. H., Salen, K., \& Wortman, A. (2019). Affinity online: How connection and shared interest fuel learning. New York, NY: NYU Press.

Jenkins, H., Shresthova, S., Gamber-Thompson, L., KliglerVilenchik, N., \& Zimmerman, A. (2016). By any media necessary: The new youth activism. New York, NY: NYU Press.

Kligler-Vilenchik, N., \& Literat, I. (2018). Distributed creativity as political expression: Youth responses to the 2016 US presidential election in online affinity networks. Journal of Communication, 68(1), 75-97.

Literat, I., Kligler-Vilenchik, N., Brough, M., \& Blum-Ross, A. (2018). Analyzing youth digital participation: Aims, actors, contexts and intensities. The Information Society, 34(4), 261-273.

Marquart, F., Ohme, J., \& Möller, J. (2020). Following politicians on social media: Effects for political information, peer communication, and youth engagement. Media and Communication, 8(2), 197-207.

Reinikainen, H., Kari, J. T., \& Luoma-aho, V. (2020). Generation $Z$ and organizational listening on social media. Media and Communication, 8(2), 185-196.

Renninger, B. (2015). "Where I can be myself...where I can speak my mind": Networked counterpublics in a polymedia environment. New Media \& Society, 17(9), 1513-1529.

Vissenberg, J., \& d'Haenens, L. (2020). Protecting youths' wellbeing online: Studying the associations between opportunities, risks, and resilience. Media and Communication, 8(2), 175-184.

Weinstein, E. (2018). The social media see-saw: Positive and negative influences on adolescents' affective well-being. New Media \& Society, 20(10), 3597-3623.

\section{About the Authors}

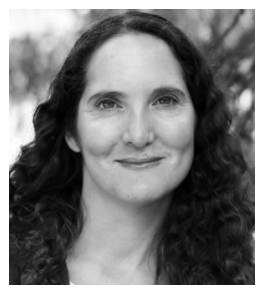

Neta Kligler-Vilenchik is Assistant Professor of Communication and Journalism at the Hebrew University of Jerusalem. Her work focuses on civic and political engagement in the context of the changing media environment, particularly among young people. Neta has published work in leading communication journals, including the Journal of Communication, New Media \& Society, International Journal of Communication, Social Media + Society, and Computers in Human Behavior. She is a Co-Author of the book By Any Media Necessary: The New Youth Activism (NYU Press, 2015). 


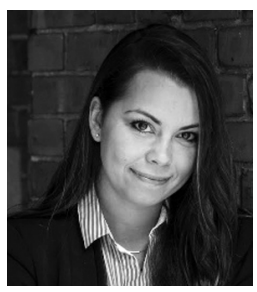

loana Literat is Assistant Professor in the Communication, Media \& Learning Technologies Design program at Teachers College, Columbia University. Her research examines creative participation in online contexts, with a particular focus on the civic dimensions of youth digital participation. Her work has been published in the Journal of Communication, New Media \& Society, Communication Theory, the International Journal of Communication, and Information, Communication \& Society, among others. 